\title{
Grupo de leitura e produção de textos: uma intervenção da terapia ocupacional
}

\section{Reading and text production group: an occupational therapy intervention}

\author{
Valéria Pacheco do Nascimentoํㅜ, Marina Esselin de Sousa Lino ${ }^{1}$, Gisele \\ Viana Campos ${ }^{1}$, Ellen Andrade ${ }^{2}$, Marisa Cotta Mancini ${ }^{3}$, Marcella \\ Guimarães Assis Tirado ${ }^{4}$
}

\begin{abstract}
NASCIMENTO, V. P.; LINO, M. E. S.; CAMPOS, G. V.; ANDRADE, E.; MANCINI, M. C.; TIRADO, M. G. A. Grupo de leitura e produção de textos: uma intervenção da terapia ocupacional. Rev. Ter. Ocup. Univ. São Paulo, v. 18, n. 1, p. 17-21, jan./abr., 2007.

RESUMO: O Grupo de Leitura e Produção de Textos foi realizado com idosos que vivem em uma instituição de longa permanência. Os objetivos do grupo foram estimular as funções cognitivas, a criatividade e a iniciativa e promover a interação entre os idosos. Após 21 sessões foi possível observar que a atividade possibilitou a ampliação da rede de contato social dos participantes, aumentou a iniciativa e favoreceu a obtenção de satisfação pessoal. Os idosos apresentaram também ganhos qualitativos de funções cognitivas como a atenção e a memória explícita. Portanto, o grupo apresentou resultados terapêuticos positivos, ilustrando um processo sistematizado de prática terapêutica ocupacional com idosos que vivem em instituições de longa permanência.
\end{abstract}

DESCRITORES: Idoso. Institucionalização. Grupo. Leitura. Escrita. Terapia ocupacional.

Acadêmicas do $10^{\circ}$ período de Terapia Ocupacional da Universidade Federal de Minas Gerais (UFMG).

2 Terapeuta Ocupacional. Especialista em Gerontologia. Prof. da Faculdade de Ciências Humanas da Fundação Mineira de Educação e Cultura (FUMEC).

3 Terapeuta Ocupacional. Doutora em Ciências da Reabilitação (Pós-Doutora). Prof. Associado do Departamento de Terapia Ocupacional da Universidade Federal de Minas Gerais (UFMG).

4 Terapeuta Ocupacional. Especialista em Gerontologia pela Sociedade Brasileira de Geriatria e Gerontologia. Doutora em Demografia. Prof. Adjunta do Departamento de Terapia Ocupacional da Universidade Federal de Minas Gerais (UFMG).

Endereço para correspondência: Valéria Pacheco do Nascimento. Rua Rio de Janeiro, 909 Apto. 803 - Bairro Centro, Belo Horizonte, MG. Cep: 30.160-041. e-mail: valeriapacheco@gmail.com 


\section{INTRODUÇÃO}

$\mathrm{O}$ avanço da idade aumenta a probabilidade de doenças e de prejuízos à funcionalidade física, psíquica e social. Mas, se os indivíduos envelhecerem com saúde, ativos, desempenhando papéis sociais, desfrutando de senso de significado pessoal e com autonomia e independência, poderão ter qualidade de vida na velhice (PASCHOAL, 2000).

Por outro lado, idosos que residem em instituições de longa permanência, e que se encontram inativos, têm seu potencial intelectual reduzido, e sua criatividade e relacionamento social afetados. A ausência de relações sociais priva o indivíduo de essenciais apoios emocionais e físicos (SÉ; LASCA, 2005).

Neste contexto, a intervenção terapêutica ocupacional visa manter, restaurar e melhorar a capacidade funcional, conservando o idoso ativo e independente o maior tempo possível (BARRETO; TIRADO, 2006). Destaca-se ainda a importância de manter a participação do idoso nas atividades cotidianas, preservando o senso de bem-estar e a qualidade de vida (TIRADO, 2004; BONDER, 2001).

A atenção em terapia ocupacional com o idoso em instituição de longa permanência pode ocorrer de formas distintas; individualmente ou em grupos. O presente estudo abordará o relato de um trabalho em grupo com idosos.

A intervenção com idosos, em grupos, adquire importância, no sentido de favorecer o bem-estar e estimular a reconstrução da identidade e, conseqüentemente, promover o resgate de capacidades e de vínculos sociais (ZIMERMAN, 1997; DEPS, 1999).

Os grupos podem fornecer oportunidades para partilhar experiências por meio de discussões e de desenvolvimento de programas de atividades, enfim, possibilitam manter e/ou estimular a atividade mental e a interação social. Portanto, devem ser incentivados nas instituições de longa permanência para idosos, uma vez que podem contribuir na prevenção do declínio cognitivo e na ampliação das redes de contato social (NEGREIROS, 2003; GUERREIRO, CALDAS, 2001).

O Grupo de Leitura e Produção de Textos aqui apresentado, foi realizado com idosos em uma instituição de longa permanência, durante o estágio curricular do curso de graduação em terapia ocupacional da Universidade Federal de Minas Gerais (UFMG). O grupo foi coordenado por uma estagiária e supervisionado pela professora da UFMG e pela terapeuta ocupacional da instituição. Participaram das discussões do trabalho outras duas acadêmicas e mais uma docente da UFMG.

Os objetivos do grupo foram: 1) estimular as funções cognitivas (incluindo a atenção, a concentração e a memória), a criatividade, iniciativa e a orientação espaçotemporal; 2) promover a interação entre os idosos.

\section{MATERIALEMÉTODOS}

O Grupo de Leitura e Produção de Textos foi realizado em uma instituição de longa permanência, com capacidade para 30 idosos de ambos os sexos e diagnósticos variados, no município de Belo Horizonte, MG, Brasil. No ano de 2006, de março a julho, foram realizadas 21 sessões, que ocorreram no período vespertino, duas vezes por semana uma, na qual os textos eram produzidos, e a outra, para organização desses nos murais da instituição.

Participaram do grupo idosos com interesse pela leitura e escrita e que apresentavam comprometimentos cognitivos leves. As atividades do grupo foram desenvolvidas na sala de Terapia Ocupacional da instituição e este foi composto por nove idosos, sendo dois do sexo masculino, com idade entre 73 e 86 anos e com os seguintes diagnósticos: transtorno depressivo, transtorno cognitivo leve, sintomas psicológicos e comportamentais da demência (SPCD), e provável Demência de Alzheimer, na fase inicial. Cabe destacar que o número de participantes variou no decorrer dos encontros, com uma média de três participantes por sessão, já que a participação no grupo foi facultativa.

Os objetivos traçados inicialmente para o Grupo de Leitura e Produção de Textos, e as anotações descritivas das sessões, documentadas por meio de relatórios individuais que foram elaborados pela coordenadora e descreviam o desempenho dos participantes do grupo, foram utilizados como parâmetros para análise e discussão dos resultados.

\section{DINÂMICADOGRUPO}

\section{a) Abertura}

$\mathrm{Na}$ abertura do grupo dois objetivos eram prioritariamente abordados: a promoção de interação entre os idosos e a orientação espaço-temporal. Os encontros iniciavam-se com a apresentação da coordenadora do grupo e de cada componente e posterior distribuição de crachás, com a finalidade de facilitar o reconhecimento e a interação entre os idosos. No primeiro encontro, foi firmado o contrato terapêutico, e informado aos participantes sobre os dias e os horários de atividades do grupo.

Em seguida, visando à orientação espaço-temporal, era realizada a Terapia de Orientação para Realidade (TOR), na qual se trabalhavam os aspectos temporais (dia, mês e ano) e espaciais (local de realização do grupo, nome da 
instituição, cidade e Estado) com auxílio de pistas verbais e visuais por meio de um mural na parede (BOTTINO et al., 2002; KASHIMA et al., 1999).

\section{b) Leitura e discussão dos textos}

Após a apresentação, passava-se à leitura. Diferentes temas e formatos textuais foram trabalhados nos encontros. No decorrer das sessões, utilizaram-se contos, "pensamentos", reportagens e textos temáticos sobre o processo de envelhecimento, relações humanas e festividades. Os textos eram fornecidos pela coordenadora; e os temas, escolhidos pelos idosos.

Antes do início da leitura, a coordenadora explicava aos participantes qual era a proposta do encontro, por exemplo, ler um texto e, mais tarde, dar a opinião a respeito dele ou dissertar sobre o tema em questão, ou escrever livremente sobre determinado tema. Essa estratégia era utilizada para que os idosos pudessem direcionar sua escuta durante a leitura, objetivando principalmente estimular a atenção, a memória e a concentração. Gomes e Boruchovitch (2005) enfatizam que os propósitos do leitor determinam as estratégias utilizadas para a compreensão.

Posteriormente, era realizada a leitura do texto, em alguns encontros pelos próprios participantes e em outros pela coordenadora, e, antes de dar início à produção, os integrantes discutiam sobre a interpretação desse texto.

A leitura envolve uma variedade de habilidades como por exemplo, identificação de letras, reconhecimento de palavras e integração de informações, além de processos de percepção, memória, inferência, dedução e processamento estratégico, portanto, é uma atividade cognitiva por excelência (FERREIRA, DIAS, 2002; KLEIMAN, 1995).

Entretanto, cabe destacar que a compreensão durante o processo de leitura depende de variáveis individuais, como personalidade, habilidades intelectuais, cultura e o contexto (SÉ \& LASCA, 2005).

\section{c) Produção dos textos}

Após leitura e discussão dos temas, iniciava-se a produção dos textos. Nessa fase do grupo, os objetivos abordados foram a estimulação da criatividade e da iniciativa e a promoção da interação entre os participantes.

Nas primeiras sessões, os idosos demonstraram dificuldades para iniciar a redação dos seus textos. Visando solucionar tais dificuldades, uma estratégia empregada, no decorrer dos encontros, foi estimular a participação de todos durante a discussão e chamar a atenção para as opiniões diferentes que surgiam. Outra tática foi a graduação das atividades propostas. Inicialmente foram utilizados contos mais curtos e, em seguida, contos mais longos.

A coordenadora fazia a leitura de parágrafos ou frases lentamente e repetia sempre que solicitado. Num momento posterior, os contos foram substituídos por reportagens e/ ou textos temáticos, e finalmente foram utilizados "pensamentos" visando à estimulação da capacidade de abstração e à escrita mais livre dos idosos. Nos últimos encontros, esses passaram a escrever seus textos livremente, e as leituras iniciais foram interrompidas.

Durante o processo de produção, alguns participantes solicitavam o auxílio da coordenadora para o desenvolvimento ou a finalização de seus textos, o que era repassado aos outros integrantes do grupo. Para tanto, esses deveriam ler seu texto em voz alta para que os demais os auxiliassem em sua questão.

Ao longo das 21 sessões, os idosos elaboraram textos que trataram dos seguintes temas: Escrita (sua importância e utilização); Auto-aceitação (valorização das características pessoais); Natureza (preservação ambiental e manutenção dos recursos naturais); Festividade religiosa - Páscoa (seu significado e importância pessoal); Relações Humanas (convivência, interação, ajuda e respeito ao próximo); Envelhecimento (aspectos emocionais, físicos e socais)

Nos últimos encontros, não foram fornecidos temas, a fim de possibilitar a autonomia e a escolha dos idosos.

Rance e Price (1973), referindo-se à escrita criativa, destacam que a resistência para expressão é freqüentemente reduzida e as fantasias podem ser expressas, sem a exigência de aprovação ou receio de desaprovação.

Durante os encontros, foi possível observar que os textos foram se tornando mais detalhados e criativos, e que os participantes passaram a escolher os temas com maior iniciativa e interesse.

\section{d) Encerramento}

Após o término das produções, os participantes eram solicitados a ler seus textos em voz alta, e, em seguida, o grupo emitia, ou não, a opinião a respeito. Posteriormente, a coordenadora realizava o convite para o encontro seguinte, informando dia, horário e local, e estimulava os participantes a trazer textos de seu interesse para ser trabalhados. Finalizava-se com Orientação para a Realidade.

\section{e) Mostra dos Textos}

A coordenadora do grupo propôs aos participantes a realização de uma "mostra" dos trabalhos nos murais da instituição. Os textos foram editados em letras grandes juntamente com fotos recentes dos autores. A realização da mostra estimulou os participantes a investir em novas 
produções, elevou a sua auto-estima, aumentou o seu sentimento de utilidade e a interação do grupo. Também funcionou como uma espécie de "convite informal" para os demais idosos da instituição, que, por meio da visualização do trabalho concreto daqueles participantes, foram incentivados a participar do grupo.

\section{f) Construção do Álbum}

Os dois últimos encontros do grupo foram dedicados à confecção do álbum do Grupo de Leitura e Produção de Textos, que continha as fotos dos idosos juntamente com os textos produzidos.

\section{DISCUSSÃO}

Os encontros do Grupo de Leitura e Produção de Textos, na avaliação da coordenadora e na percepção dos idosos, contribuíram para promoção de mudanças em diversos desfechos clínicos, que foram definidos como objetivos terapêuticos para as sessões. Foi observada e percebida melhora na interação social entre os participantes, que passaram a conversar de forma mais espontânea e freqüente durante as sessões e também em outros horários. Observou-se ainda que os idosos apresentavam-se mais atentos e concentrados durante as sessões, com participação mais ativa nas atividades propostas, ilustrando possíveis mudanças na atenção, concentração, memória e na iniciativa. Ao final dos encontros, foi observada maior espontaneidade dos participantes diante das propostas apresentadas, em comparação com as primeiras sessões. Eles foram adquirindo, durante os encontros, maior autonomia e independência na leitura, interpretação, elaboração e redação de textos, solicitando cada vez menos o auxílio da coordenadora, sobretudo nas últimas sessões, nas quais não foi necessário fornecer nenhum auxílio.

Ao longo do processo, os idosos foram estimulados a exercitar a criatividade e passaram a escrever de forma mais livre, criativa e poética. Observou-se ainda maior expressão de sentimentos, uma vez que eles compartilharam fatos significativos e experiências de vida. Os participantes foram também estimulados a desenvolver estratégias para a realização das atividades propostas e mostraram maior compromisso com o grupo e preocupação com o resultado dos textos.

Observou-se que a realização da mostra foi considerada um marco importante no processo terapêutico do grupo. Segundo relatos dos participantes, por meio dela foi possível expor o trabalho realizado a toda a instituição. Salienta-se que funcionários, familiares, visitantes e os outros idosos elogiaram os autores pelo trabalho realizado, e alguns até solicitaram cópias dos textos expostos. Esse reconhecimento possibilitou a satisfação pessoal deles, o aumento da auto-estima e do sentimento de utilidade.

Finalmente, ressalta-se que a confecção do álbum foi fundamental para o fechamento das atividades realizadas no grupo. A compilação de todo o trabalho produzido com fotos dos autores ao lado de suas produções possibilitou a visualização do percurso realizado ao longo das 21 sessões.

Após a apreciação do álbum finalizado, a coordenadora realizou o encerramento do grupo. Eis o depoimento de uma participante: "Você abriu uma porta, e uma porta bem aberta!" (sic).

\section{CONSIDERAÇÕES FINAIS}

O Grupo de Leitura e Produção de Textos constitui um relato de experiência no atendimento a idosos institucionalizados, e possibilitou a interação dos participantes, contribuindo para a promoção de funções cognitivas, da criatividade e da iniciativa, bem como para o crescimento pessoal e contrabalançando as perdas comuns a esse estágio da vida. Portanto, o grupo apresentou resultados terapêuticos positivos, ilustrando um processo sistematizado de prática terapêutica ocupacional com idosos que vivem em instituições de longa permanência.

NASCIMENTO, V. P.; LINO, M. E. S.; CAMPOS, G. V.; ANDRADE, E.; MANCINI, M. C.; TIRADO, M. G. A. Reading and text production group: an occupational therapy intervention. Rev. Ter. Ocup. Univ. São Paulo, v. 18, n. 1, p. 17-21, jan./abr., 2007.

\begin{abstract}
Group activity focusing on reading and text production was conducted with elderly living in a long stay institution. The group objectives were to stimulate cognitive functions, creativity and initiative, besides promoting the interaction among the elderly. After 21 sessions, it was possible to observe that the activities allowed a broadening of the participants' social interaction network, improved the initiative and favored the attainment of personal satisfaction. The elderly also showed qualitative gains in cognitive functions such as attention and explicit memory. In conclusion, the group showed positive therapeutic outcomes, illustrating a systematic occupational therapy process with elderly who live in long stay institutions.
\end{abstract}

KEY WORDS: Elderly. Institutionalization. Group. Reading. Writing. Occupational therapy. 


\section{REFERÊNCIAS}

BARRETO, K. M. L.; TIRADO, M. G. A. Terapia Ocupacional em Gerontologia. In: FREITAS, E. V. de et al. Tratado de Geriatria e Gerontologia. Rio de Janeiro: Guanabara Koogan, 2006. p. 12101215 .

BONDER,B.R. Wellness In: BONDER,B.R.; WAGNER,M.B. Functional Performance in Older Adults. Philadelphia: F.A. Davis Company, 2001. p. 321-338.

BOTTINO et. al. Reabilitação cognitiva em pacientes com doenças de Alzheimer: relato de trabalho em equipe multidisciplinar. Arquivos de Neuro-Psiquiatria, São Paulo, v. 60, n. 1, p.70-79, mar. 2002.

DEPS, V. L. Atividade e bem-estar psicológico na maturidade In: NERI, A. L.; SILVA, E. B. N. (Org.). Qualidade de vida e idade madura. Campinas: Papirus, 1993. p.57-82

FERREIRA, S. P. A.; DIAS, M. G. B. B. Compreensão de leitura: estratégias de tomar notas e da imagem mental. Psicologia Teoria e Pesquisa [on-line], v. 18, n. 1, p. 51-62, jan./abr. 2002. Acesso em: <http://www.scielo.br>.

GOMES, M. A. M.; BORUCHOVITCH, E. Desempenho no jogo, estratégias de aprendizagem e compreensão na leitura. In: Psicologia Teoria e Pesquisa [on-line], v. 21, n. 3, p. 319-326, set./dez. 2005. Acesso em: 〈http://www.scielo.br〉.

GUERREIRO, T.; CALDAS, C. P. Memória e demência: (re) conhecimento e cuidado. Rio de Janeiro: UERJ, UnATI, 2001. 209 p.

Recebido para publicação: Jan./2007

Aceito para publicação: Fev./2007
KASHIMA, H. et al. Current trends in cognitive rehabilitation for memory disorders. Keio Journal of Medicine, Tokyo, v.48, n.2, p. 79-86, jun. 1999.

KLEIMAN, A. Oficina de leitura: teoria e prática. Campinas: Editora da Universidade Estadual de Campinas, 3. ed., 1995. 102p.

NEGREIROS, T. C. G. M. (Org.). A nova velhice. Uma visão multidisciplinar. Rio de Janeiro: Revinter, 2003. 146p

PASCHOAL, S. M. P. Qualidade de vida do idoso: Elaboração de um instrumento que privilegia sua opinião (dissertação). São Paulo: Faculdade de Medicina, Universidade de São Paulo, 2000.

RANCE, C.; PRICE, A. Poetry as a group project. The American of Occupational Therapy. v. 27, n. 5, p. 252-255, 1973.

SÉ, E. V. G.; LASCA, V. Exercite sua mente: guia prático para aprimoramento da memória, linguagem e raciocínio. São Paulo: Prestígio, 2005. 158p.

TIRADO,M.G.A. Reabilitação e manutenção da capacidade funcional. In: SALDANHA, A.L.; CALDAS, C.P. (org.) Saúde do idoso - a arte de cuidar. Rio de Janeiro: Interciências, 2004. p.144-151.

ZIMERMAN, G. I. Grupos com idosos. In: ZIMERMAN. D. E.; OSORIO, L. C. et. al. Como trabalhamos com grupos. Porto Alegre: Artes Médicas, 1997. p.331-342. 